\title{
Do New Technology Characteristics Influence Intention to Adopt for Manufacturing Companies in Malaysia?
}

\author{
Ahmad Shahir Abdul Aziz \\ InvestPerak, Malaysia \\ shahir@investperak.gov.my
}

\author{
Nabsiah Abdul Wahid * \\ Graduate School of Business \\ Universiti Sains Malaysia (USM) \\ nabsiah@usm.my
}

\begin{abstract}
Today, the world has acknowledged the importance of technology as a tool to enhance company's performance. It is observed that industries globally have started to embrace new technology which is in line with fourth industrial revolution or better known as Industry 4.0 that occurs in the marketplace. In Malaysia however, the embracement of technology is observed to be quite slow compared to those neighboring countries such as Singapore and Thailand. This study thus investigates whether intention to adopt new technology of Cyber-Physical Systems (CPS) by selected manufacturing industries in Malaysia is influenced by characteristics of technology itself. For this study, four characteristics, namely, relative advantage, compatibility, complexity and trialability of technology are being investigated as possible influencers of company's intention to adopt new technology. Based on statistical analyses on one hundred manufacturers that took part in the study's survey, the findings show that compatibility of technology is the only factor that shows significant direct influence for new technology adoption intention while other three characteristics, namely, relative advantage, complexity and trialability show no significant relationship at all. The findings indicate that for manufacturing companies in Malaysia, their intention to adopt mainly depends on whether the new technology is compatible with the existing technology they have. This implies that the manufacturing industry in the country is a bit conservative in their decision making in relation to adoption of new technology.
\end{abstract}

Keywords: Industry 4.0, relative advantage, compatibility, complexity, trialability, technology adoption intention

\section{INTRODUCTION}

To date, the fourth industrial revolution (IR4.0) or better known as Industry 4.0 is becoming increasingly significant as it affects industries worldwide. The new technology advancement has evolved rapidly which forces manufacturers to operate in a challenging and dynamic environment. Firms found themselves forced to move forward either by trying to be innovative on their own effort, to adapt or to adopt the new technology introduced in the marketplace so that they can be in tandem with current technology applied and be competitive in the era of IR4.0.

The history of IR4.0 actually started way off in the second half of the 18th century when the first industrial revolution started with the introduction mechanical production. The electrification and the division of labour in the 1870 s formed the second industry revolution followed by the third phase of revolution in 1970s with the usage of advanced electronics and information and communication technologies (ICT). Today, Cyber-Physical Systems (CPS) marks the latest stage of revolution or IR4.0 [1].

The main roles of CPS are to fulfil the agile and dynamic requirements of production, and to improve the effectiveness and efficiency of the entire industry [1]. The term "Cyber-Physical Systems" (CPS) was invented in 2006 during a working group session among high-level experts from USA and European Union to support the coexistence of cyber and physical elements with a common goal [2]. Even though the embedded systems have been developed and adopted over the past decades, the integration between computation and physical process is becoming increasingly important to accommodate the emerging technology and business needs by manufacturing players.

In Malaysia, Industry 4.0 is critical as its adoption is believed to help improve governance, to accelerate innovation, to boost productivity, to move industries up the value chain and to help enhance the wellbeing of the people in the country. The benefits that are believed to be far and wide have seen the government to initiate the formulation of new policy and regulation, namely, the National Policy on Industry 4.0 (Industry4WRD) to encourage manufacturing companies adopting the new technology in tandem with the current Industry 4.0 [3]. The government believes that Malaysia needs to speed up the adoption process as within the South East Asia region, the country is lagging behind countries like Singapore and Thailand who are already in the 
transition towards IR4.0. In Malaysia, many of the existing manufacturing firms are still in the 2.0 and 3.0 stages as some of them prefer to keep employing foreign workers instead of investing in automation [4]. While the intent to speed up the adoption process is seriously upheld, the Ministry of International Trade and Industry (MITI, n.d.) has managed to identify five contributing factors towards the slow-adoption IR4.0 phenomenon amongst manufacturing firms.

The first factor relates to the lack of firm's awareness on the importance of Industry 4.0 as well as on what advantages it can offer to the firm. The second factor is due to insufficient infrastructure developed by relevant parties to support the ecosystem. The third factor emphasizes on unclear policy and lack of special incentives to promote more companies to adopt Industry 4.0 in Malaysia. The fourth and the fifth factors pinpoint to the lack of standards which affect the integration process of different systems; and to the mismatched skillsets and lack of right talent to support the execution respectively. MITI believes that these five factors pose the Ministry with serious problems that if they are not tackled, then, the intent to be part of IR4.0 will be diminished. Thus, it is now crucial for the Ministry, all relevant government bodies and the private sectors to team up in addressing the problems so that the adoption of Industry 4.0 and CPS technology can be expedited in line with the need to keep our industry more competitive and abreast with other emerging economies. A research had warned on the challenges that come side by side with the adoption of Industry 4.0; these challenges, namely, interoperability, predictability, security, reliability, dependability and sustainability (e.g. requirement of new functional areas such as storage, real-time processing, and accessibility) [5].

In addition, Thramboulidis [6] caution firms on the requirement for companies to adopt sophisticated system that can support the new technology adoption made like cloud computing and the Internet of Things (IoT) to extend their adoption capabilities. There is also further need for firms to make additional capital investment and arrange for placement of sophisticated sensor network architectures to ensure the abundant storage capabilities, real-time processing and the seamless access of computation-physical devices for smooth integration of the new technology [7]. What these indicate is that manufacturing firms need to realize and have the ability to invest more in the new technologies, buy on more sophisticated equipment, as well as employing skilled workers that can take up and matched to the new tasks when they decide to adopt IR4.0. As IR4.0 is about new technology that is expensive and can be complicated to adopt, to justify the benefit of Industry 4.0 adoption, the manufacturing firms must obtain an in-depth understanding of the factors that affect their management's intention towards adopting CPS. While other factors can be at play like the organizational and marketplace environment, for this study though, the investigation is focused on finding whether intention to adopt new technology by manufacturing industries in Malaysia is influenced by characteristics of the technology itself. Since the study is exploratory, the focus of the new technology is set to be on CPS while the scope is limited to 100 manufacturing firms that participated in the study.

\section{MATERIALS AND METHODS}

\section{A. Literature Review and Hypotheses Development}

The importance of technology is acknowledged in the literature. Past studies have focused on identifying and examining the characteristics of technology. The popular characteristics applied by researchers alike are those suggested by [8], namely, relative advantage, compatibility, complexity, triability and observability that are said to be technological characteristics that can determine new technology adoption in the marketplace.

The first characteristic, i.e. relative advantage is also known as perceived benefits. It has consistently been identified as a predictor of adoption intention in previous innovation research $[9,10,11,12,13]$. In [13] study for example, relative advantage factor was found to play a vital role in influencing organization to adopt to cloud computing. The finding was supported by [14] which shows that perceived direct benefits and indirect benefits become the key factors in affecting hotel's initial decision to adopt information and communication technology (ICT) and continued the adoption decisions. A study focused on Radio-frequency identification (RFID) adoption intention by [11] also indicated the significance of RFID's relative advantage variable. Nevertheless, there were several researches indicated the negative relationship between perceived relative advantage and technology adoption intention. For instance, [15] in their research on serviceoriented architecture (SOA) Architects among South African organizations showed that perceived relative advantage has no effect on adoption. This finding was also supported by other researchers in different contexts that show the existence of the negative relationships $[16,17,18]$.

From these literature support, hypothesis 1 is proposed:

H1: Relative advantage of technology determines manufacturing firm's intention to adopt new technology of CPS.

The second characteristic is compatibility. According to [19], compatibility can be described as the firm's chances to gain advantage which should be higher if the firm finds it easier to incorporate the new technology with existing systems that are currently used by the firm. In view of this notion, [20] explained that the lack of adaptability of the new technology with the organizational processes and the existing technologies (referring to compatibility) were the 
reason for the most failure cases in technology adoption. Since then, compatibility has been suggested as the main predictor of technology adoption in previous researches $[10,12,14,21,22,23]$. Furthermore, recent studies have clearly addressed the importance of compatibility for technology adoption. [11] and [13] in their research found that compatibility has significant relationship with technology adoption. The findings were supported by [23] in their research on small to medium-sized enterprises' (SMEs') adoption of enterprise applications (EA). Nevertheless, [24] in their research indicated that compatibility has insignificant relationship with Building Information Modelling (BIM) adoption in India. It happened due to India has been a late entrant in the BIM adoption process and therefore adopters of BIM do not have a critical mass of early adopters to follow and learn. However, it is different with cloud computing adoption which the recent research indicated that compatibility has significant relationship with cloud computing adoption in India [25]. The negative relationship between compatibility and technology adoption was also found by [18] in their research on Social CRM among SME sector in Malaysia.

From these literature support, hypothesis 2 is proposed:

H2: Compatibility of technology determines manufacturing firm's intention to adopt new technology of CPS.

The third characteristic of technology is complexity. Complexity refers to the degree to which an innovation is perceived as relatively difficult to understand and use. Usually, complexity is negatively associated with adoption since it can be a deterrent to successful implementation $[13,17,23,25]$. It is due to the characteristics of the new technology is perceived to be complex even though it provides benefits to the organization. Therefore, it has been suggested to be used as a main predictor of technology adoption in previous research [11,14,21,23]. For instance, a study carried out among 280 companies in the IT, manufacturing and finance sectors in India recently on cloud computing adoption at organizational level found that complexity is negatively associated with company's adoption intention [25]. This finding was supported by [17] study which shows that complexity is significantly negatively related to hotels' adoption of mobile hotel reservation systems (MHRS). Nevertheless, [11] in their research on Radio Frequency Identification (RFID) adoption among SME Sector in USA, UK Australia and India found that complexity factor was not a determinant for the RFID adoption. This unanticipated result was found due to the uniqueness of RFID technology which has not been complex for adoption. This finding was also supported by other studies [15,16,24,26,27].

From these literature support, hypothesis 3 is proposed:
H3: Complexity of technology determines manufacturing firm's intention to adopt new technology of CPS.

Apart from the three characteristics, triability is another characteristic of technology that is also popular amongst researchers. Rogers [8] proposed 'trialability' as one of important factors for technology adoption. Trialability is defined as testability which the new technology can be tested or used before full adoption. Even though trialability factor was not part of Technology-OrganizationEnvironment (TOE) framework that is mostly applied by researchers in investigating technology adoption studies, previous studies have clearly showed that it has positive effect for technology adoption [23][28]. This factor becomes important to be integrated with the TOE framework since the adoption of CPS technology is complex to implement especially for existing manufacturers in Malaysia compared to other manufacturers in developed countries. Furthermore, since most of the existing manufacturing industry in Malaysia is still between 2.0 and 3.0 of industrial revolution, it is a necessary for them to learn more and test the technology on trial basis. On top of that, recent study [24] on building information modelling (BIM) proved that trialability has significant impact with technology adoption. Nevertheless, [15] in their research on service-oriented architecture (SOA) Architects among South African organizations shows that technology implementation concern did not has effect on technology adoption.

From these literature support, hypothesis 4 is proposed:

H4: Triability of technology determines manufacturing firm's intention to adopt new technology of CPS.

As a note, although the last characteristic of technology, namely, observability is suggested by [8], it is not included in this study.

\section{B. Research Method}

In this study, the population of study is manufacturing firms that covers all sectors in the manufacturing industry. However, since this study was exploratory in nature and was also bounded by time, money and workforce access issues, the sample is limited to only 100 manufacturing firms (managerial level) that have not adopted CPS technology. These firms were from all manufacturing subsectors mentioned under Industry4WRD policy (e.g. electrical and electronic (E\&E), chemicals, machinery and equipment, medical devices and aerospace, automotive, transport, textiles, pharmaceutical, metal, and food processing) that are identified as key drivers to manufacturing growth. They were selected based on purposive sampling criteria. In purposive sampling, the researcher formulates the sample based on researcher's own experience and judgment on informants' specific qualities that are of the researcher's 
interest in the attempt to answer the research questions $[29,30]$. Although it is purposive, this sampling technique can still help to ensure a fair and objective version of the sampled respondents. Respondents in the study were those that attended one of the special seminars organized by MITI for all manufacturing firms in Malaysia to promote IR4.0 and related issues. The respondents were given and asked to complete a set of questionnaires that focused on the variables of interest; namely, intention to adopt technology, relative advantage, compatibility, complexity, triability, as well as background information of the companies. Item questionnaires were adapted or adopted from past studies.

For data analysis, this study utilized partial least squares structural equation model (PLS-SEM 3.0) to help explain the relationship among the variables [31,32]. SEM is a procedure to assess a research model with a linear relationship among the observed variables. In this research, SEM was used to measure the relationship among the variables in the proposed research model of this study. There were several reasons for using SEM.

\section{RESULTS AND DISCUSSION}

Of the total 100 survey questions distributed, the top three of the firms participated in the study were from the Electrical and Electronic (E\&E) (25.3\%), Machinery and Equipment (15.9\%) and Medical Devices (14.7\%). The majority of the firms were 100\% Malaysian owned (35.3\%); the firms were very much experienced with $55.9 \%$ of the companies have been established and in business since more than twenty years ago. The majority of these companies were from Perak state compared to other states in Malaysia.

TABLE 1. RESUlts ON HYPOTHESES TESTING

\begin{tabular}{|c|l|c|c|c|}
\hline Hypothesis & \multicolumn{1}{|c|}{ Path } & t-value & $\begin{array}{c}\mathrm{p}- \\
\text { value }\end{array}$ & Supported \\
\hline $\mathrm{H} 1$ & $\begin{array}{l}\text { Relative Advantage } \rightarrow \\
\text { Adoption Intention }\end{array}$ & 0.488 & 0.626 & NO \\
\hline $\mathrm{H} 2$ & $\begin{array}{l}\text { Compatibility } \rightarrow \text { Adoption } \\
\text { Intention }\end{array}$ & 2.316 & 0.021 & YES \\
\hline $\mathrm{H} 3$ & $\begin{array}{l}\text { Complexity } \rightarrow \text { Adoption } \\
\text { Intention }\end{array}$ & 0.497 & 0.619 & NO \\
\hline $\mathrm{H} 4$ & $\begin{array}{l}\text { Trialibility } \rightarrow \text { Adoption } \\
\text { Intention }\end{array}$ & 1.432 & 0.153 & NO \\
\hline
\end{tabular}

Table 1 shows the results found on hypotheses testing. Of all the four hypotheses tested, only compatibility characteristic (H2) shows significant result over new technology adoption by the manufacturing firms. The first hypothesis for instance, found that relative advantage was insignificant with adoption intention ( $\mathrm{t}$-statistic $=0.488 ; \mathrm{p}$ values $=0.626$ ). This result does not support the mainstream results of current studies, which indicated the positive relationship between perceived relative advantage and adoption intention of innovation technology [11, 13,14,27].
The reason for the insignificant findings could perhaps be that CPS technology perceived relative advantage cannot significantly influence firms' intention to adopt it. Since the existing manufacturing industry in Malaysia is between second and third stage of industrial revolution, they feel complacent and comfortable with the existing technology they are using and do not concern with benefit or advantage of using CPS technology in their firms. Furthermore, since CPS technology in Malaysia is still in its infancy and relatively new to the existing manufacturing firms, they may not have confidence in CPS technology compared to other technologies which have established well in this country.

Likewise, this situation happened to the RFID system technology when it was first introduced which found that firms are more concerned to the potential problems or risks of RFID systems than to the potential benefits or advantages in deciding whether or not to adopt the new technology. Besides, since firms during that time was thinking that they do not have sufficient technical capabilities to adopt new technology, they would rather use their current systems and this phenomenon may also make relative advantage to be insignificant factor for RFID adoption intention [22]. The study's finding contradicts other technologies studies such as mobile marketing and electronic supply chain management system as the current studies found that for the latter technologies, perceived relative advantage was found to have a significant relationship with technology adoption $[16,27]$.

As for the second hypothesis (H2), the finding from the present study concurs with past literature that compatibility of technology is positively related with adoption intention $(\mathrm{t}$-statistic $=2.316 ; \mathrm{p}$ values $=0.021)$. This finding provides evidence that compatibility is significantly associated with manufacturing firms' intention to adopt CPS. This finding showed that the compatibility of technology is the major concern for adoption intention. This is supported by similar results found from past studies $[11,15,16,23,28,33]$. In the context of Malaysia, the adoption of CPS and Industry 4.0 technology are relatively new and still in the infant stage. Therefore, the chances of firms to adopt CPS technology is higher if they found easier to integrate such a new technology with their existing systems.

The third hypothesis (H3) focused on the relationship between complexity characteristic and manufacturing firm's intention to adopt CPS technology. Similar to H1, the result shows that there is no significant relationship between complexity and CPS adoption intention ( $\mathrm{t}$ - statistic $=0.497$; $\mathrm{p}$ values $=0.619)$. Although the finding shows inconsistency with other results from past studies [17, 23,25] who found that complexity has significant relationship with technology adoption, it is very much in support of [27]. In their study, they found no significant relationship between perceived complexity and mobile marketing adoption intention which leads them to suggest that SMEs are not influenced by the complexity of mobile marketing in their adoption intention. 
Similar conclusion can be made for adoption intention of the CPS technology as in this current study. The reason for this may be due to the infancy of the CPS technology in Malaysia, that the firms may not be familiar with the technology as CPS itself represents the extension of third industrial revolution in which the ICT and advanced electronics were used. Thus, firms' familiarity with technology may be the eliminating factor on the importance of complexity in determining adoption intention as suggested by [34].

The last hypothesis (H4) focused on investigating the influence of trialability as the determinant for CPS technology adoption intention. The current study found that triability has no significant relationship with manufacturing firm's CPS adoption intention ( $\mathrm{t}$-statistic $=1.432 ; \mathrm{p}$ values $=0.153)$. The present result shows conflicting results with previous studies $[23,24,28]$ which showed that triability played a role in adoption intention of technology. This insignificant finding however is in line with previous research by [35] who focused on cloud computing technology adoption, as well as by [15] who emphasized on service-oriented architecture (SOA) among South African organizations. In the Malaysian context, the result may be due to most of the manufacturing firms who participated in this study are $100 \%$ Malaysian-owned. Thus, triability may then be considered not a critical factor for them since most of the local companies are not well exposed to the CPS technology. Perhaps, testing would be more relevant to larger companies especially multinational companies (MNCs) which are less represented in this study.

\section{CONCLUSION}

In conclusion, based on statistical analyses on 100 respondents from manufacturing firms, the findings show that compatibility of technology is the only factor that shows significant direct influence for new technology adoption intention while other three characteristics, namely, relative advantage, complexity and trialability show no significant relationship at all. The findings indicate that for manufacturing companies in Malaysia, their intention to adopt mainly depends on whether the new technology is compatible with the existing technology they have or not. This implies that the manufacturing industry in the country is a bit conservative in their decision making in relation to adoption of new technology.

\section{REFERENCES}

[1] Y. Liao, F. Deschamps, E.F.R. Loures, and L.F.P. Ramos. (2017). Past, present and future of Industry 4.0 - a systematic literature review and research agenda. International Journal of Production Research, 55(12) 3609-3629.

[2] NSF Workshop on Cyber-Physical Systems. (2006, October 16-17). Retrieved from http://varma.ece.cmu.edu/cps/
[3] Ministry of International Trade and Industry (MITI). (2018). FAQs on Industry 4.0 http://www.miti.gov.my/index.php/pages/ view/industry4.0? mid $=559$

[4] K.B. Ooi, V.H. Lee, G.W.H. Tan, T.S. Hew, \& J.J. Hew. (2018) Cloud computing in manufacturing: The next industrial revolution in Malaysia? Expert Systems with Applications, 93, 376-394.

[5] Gunes, V., Peter, S., Givargis, T., \& Vahid, F. (2014). A survey on concepts, applications, and challenges in cyber-physical systems. KSII Transactions on Internet \& Information Systems, 8(12).

[6] Thramboulidis, K. (2015). A cyber-physical system-based approach for industrial automation systems. Computers in Industry, 72, 92102.

[7] Shi, J., Wan, J., Yan, H., \& Suo, H. (2011, November). A survey of cyber-physical systems. In 2011 international conference on wireless communications and signal processing (WCSP) (pp. 1-6). IEEE.

[8] Rogers, E. M. (1983). Diffusion of innovations. New York: Free Press.

[9] Premkumar, G., \& Roberts, M. (1999). Adoption of new information technologies in rural small businesses. Omega, 27(4), 467-484.

[10] Sharma, A., \& Citurs, A. (2005). Radio frquency identification (RFID) adoption drivers: A radical innovation adoption perspective. AMCIS 2005 Proceedings, 211.

[11] Wamba, S. F., Gunasekaran, A., Bhattacharya, M., \& Dubey, R. (2016). Determinants of RFID adoption intention by SMEs: an empirical investigation. Production Planning and Control, 27(12), 979-990.

[12] Awa, H. O., Ukoha, O., \& Igwe, S. R. (2017). Revisiting technologyorganization-environment (T-O-E) theory for enriched applicability. The Bottom Line, 30(1), 2-22.

[13] Oliveira, T., Thomas, M., \& Espadanal, M. (2014). Assessing the determinants of cloud computing adoption: An analysis of the manufacturing and services sectors. Information \& Management, 51(5), 497-510.

[14] Leung, D., Lo, A., Fong, L. H., \& Law, R. (2015). Applying the Technology-Organization- Environment framework to explore ICT initial and continued adoption: An exploratory study of an independent hotel in Hong Kong. Tourism Recreation Research, 40(3), 391-406.

[15] Maclennan, E., \& Belle, J.-P. (2014). Factors affecting the organizational adoption of service-oriented architecture (SOA). Information Systems and e-Business Management, 12(1), 71-100.

[16] Lai, H.-M., Lin, I.-C., \& Tseng, L.-T. (2014). High-Level Managers' Considerations for RFID Adoption in Hospitals: An Empirical Study in Taiwan. Journal of Medical Systems, 38(2), 1-17.

[17] Wang, Y.-S., Li, H.-T., Li, C.-R., \& Zhang, D.-Z. (2016). Factors affecting hotels' adoption of mobile reservation systems: A technology-organization-environment framework. Tourism Management, 53, 163-172.

[18] Ahani, A., Rahim, N. A., \& Nilashi, M. (2017). Forecasting social CRM adoption in SMEs: A combined SEM-neural network method. Computers in Human Behavior, 75, 560-578.

[19] Tornatzky, L., \& Fleischer, M. (1990). The processes of technological innovation. Lexington: Lexington Books.

[20] Cooper, R. B., \& Zmud, R. W. (1990). Information technology implementation research: A technological diffusion approach. Management Science, 36(2), 123-139.

[21] Brown, I., \& Russell, J. (2007). Radio frequency identification technology: An exploratory study on adoption in the South African retail sector. International Journal of Information Management, 27(4), 250-265

[22] Wang, Y.-M., Wang, Y.-S., \& Yang, Y.-F. (2010). Understanding the determinants of RFID adoption in the manufacturing industry. Technological Forecasting and Social Change, 77(5), 803-815. 
[23] Ramdani, B., Chevers, D., \& Williams, D. A. (2013). SMEs' adoption of enterprise applications: A technology-organisationenvironment model. Journal of Small Business and Enterprise Development, 20(4), 735-753.

[24] Ahuja, R., Jain, M., Sawhney, A., \& Arif, M. (2016). Adoption of BIM by architectural firms in India: technology-organizationenvironment perspective. Architectural Engineering and Design Management, 12(4), 311-330.

[25] Gangwar, H., Date, H., \& Ramaswamy, R. (2015). Understanding determinants of cloud computing adoption using an integrated TAM-TOE model. Journal of Enterprise Information Management, 28(1), 107-130.

[26] Borgman, H. P., Bahli, B., Heier, H., \& Schewski, F. (2013, January). Cloudrise: exploring cloud computing adoption and governance with the TOE framework. In 2013 46th Hawaii international conference on system sciences (pp. 4425-4435). IEEE.

[27] Maduku, D. K., Mpinganjira, M., \& Duh, H. (2016). Understanding mobile marketing adoption intention by South African SMEs: A multi-perspective framework. International Journal of Information Management, 36(5), 711-723.

[28] Alshamaila, Y., Papagiannidis, S., \& Li, F. (2013). Cloud computing adoption by SMEs in the north east of England: A multi-perspective framework. Journal of Enterprise Information Management, 26(3), 250-275.

[29] Guest, G., Bunce, A., \& Johnson, L. (2006). How many interviews are enough? An experiment with data saturation and variability. Field methods, 18(1), 59-82.

[30] Tongco, M. D. C. (2007). Purposive sampling as a tool for informant selection. Ethnobotany Research and applications, 5, 147-158.

[31] Hair Jr, J. F., Sarstedt, M., Hopkins, L., \& Kuppelwieser, V. G. (2014). Partial least squares structural equation modeling (PLSSEM). European business review.

[32] Henseler, J., Ringle, C. M., \& Sarstedt, M. (2015). A new criterion for assessing discriminant validity in variance-based structural equation modeling. Journal of the academy of marketing science, 43(1), 115-135.

[33] Ruivo, P., Oliveira, T., \& Neto, M. (2014). Examine ERP postimplementation stages of use and value: Empirical evidence from Portuguese SMEs. International Journal of Accounting Information Systems, 15(2), 166-184.

[34] Vasseur, V., \& Kemp, R. (2015). The adoption of PV in the Netherlands: A statistical analysis of adoption factors. Renewable and sustainable energy reviews, 41, 483-494.

[35] Alkhalil, A., Sahandi, R., \& John, D. (2017). An exploration of the determinants for decision to migrate existing resources to cloud computing using an integrated TOE-DOI model. Journal of Cloud Computing, 6(1), 2. 